\title{
Three traditional and three new childhood anxiety questionnaires: their reliability and validity in a normal adolescent sample.
}

Citation for published version (APA):

Muris, P. E. H. M., Merckelbach, H. L. G. J., Ollendick, T., King, N., \& Bogie, N. P. (2002). Three traditional and three new childhood anxiety questionnaires: their reliability and validity in a normal adolescent sample. Behaviour Research and Therapy, 40(7), 753-772. https://doi.org/10.1016/S00057967(01)00056-0

Document status and date:

Published: 01/01/2002

DOI:

10.1016/S0005-7967(01)00056-0

Document Version:

Publisher's PDF, also known as Version of record

Please check the document version of this publication:

- A submitted manuscript is the version of the article upon submission and before peer-review. There can be important differences between the submitted version and the official published version of record.

People interested in the research are advised to contact the author for the final version of the publication, or visit the DOI to the publisher's website.

- The final author version and the galley proof are versions of the publication after peer review.

- The final published version features the final layout of the paper including the volume, issue and page numbers.

Link to publication

\footnotetext{
General rights rights.

- You may freely distribute the URL identifying the publication in the public portal. please follow below link for the End User Agreement:

www.umlib.nl/taverne-license

Take down policy

If you believe that this document breaches copyright please contact us at:

repository@maastrichtuniversity.nl

providing details and we will investigate your claim.
}

Copyright and moral rights for the publications made accessible in the public portal are retained by the authors and/or other copyright owners and it is a condition of accessing publications that users recognise and abide by the legal requirements associated with these

- Users may download and print one copy of any publication from the public portal for the purpose of private study or research.

- You may not further distribute the material or use it for any profit-making activity or commercial gain

If the publication is distributed under the terms of Article $25 \mathrm{fa}$ of the Dutch Copyright Act, indicated by the "Taverne" license above, 


\title{
Three traditional and three new childhood anxiety questionnaires: their reliability and validity in a normal adolescent sample
}

\author{
Peter Muris ${ }^{\mathrm{a},{ }^{*}}$, Harald Merckelbach a, Thomas Ollendick ${ }^{\mathrm{b}}$, Neville King ${ }^{\mathrm{c}}$, \\ Nicole Bogie ${ }^{\text {a }}$ \\ ${ }^{\text {a }}$ Department of Medical, Clinical, and Experimental Psychology, Maastricht University, P.O. Box 616, 6200 MD \\ Maastricht, The Netherlands \\ b Virginia Polytechnic Institute and State University, VA, USA \\ ${ }^{\mathrm{c}}$ Monash University, Monash, Australia
}

Received 27 November 2000; accepted 11 April 2001

\begin{abstract}
The current study examined the psychometrics of three traditional [i.e., the trait anxiety version of the State-Trait Anxiety Inventory for Children (STAIC), the Revised Children's Manifest Anxiety Scale (RCMAS), and the Fear Survey Schedule for Children - Revised (FSSC-R)] and three new childhood anxiety scales [the Multidimensional Anxiety Scale for Children (MASC), the Screen for Child Anxiety Related Emotional Disorders (SCARED), and the Spence Children's Anxiety Scale (SCAS)] in a large sample of normal adolescents $(N=521)$. Childhood anxiety scales were generally found to be reliable in terms of internal consistency. Furthermore, evidence was obtained for the convergent and divergent validity of the various anxiety questionnaires. That is, anxiety questionnaire scores were found to be substantially intercorrelated. Particularly strong associations were found between total scores of the STAIC and the RCMAS, total scores of the SCARED and the SCAS, and between subscales that intend to measure specific categories of anxiety symptoms. Childhood anxiety questionnaires were substantially connected to an index of depression, although correlations among anxiety questionnaires were generally higher than those between anxiety scales and a measure of depression. (c) 2002 Elsevier Science Ltd. All rights reserved.
\end{abstract}

Keywords: Anxiety; Questionnaires; Reliability and validity; Adolescents

\footnotetext{
* Corresponding author. Tel.: +31-43-388-1264; fax: +31-43-367-0968.
}

E-mail address: p.muris@dep.unimaas.nl (P. Muris). 


\section{Introduction}

For children and adolescents, anxiety disorders are among the most common psychiatric disorders. Epidemiological studies have shown that between 8 and 12\% of youths suffer from anxiety complaints that are severe enough to interfere with their daily functioning (see for a review Bernstein, Borchardt, \& Perwien, 1996). During the past decade, researchers and clinicians in the field of child psychopathology have reached consensus about the various types of anxiety disorders that may occur in children and adolescents (American Academy of Child and Adolescent Psychiatry, 1997). According to the latest edition of the Diagnostic and Statistical Manual of Mental Disorders (DSM-IV; American Psychiatric Association [APA], 1994), the following anxiety disorders can be distinguished in children and adolescents: (1) separation anxiety disorder, which is characterized by excessive anxiety concerning separation from the home or from significant attachment figures, to a degree that is beyond the child's developmental level; (2) generalized anxiety disorder, formerly termed overanxious disorder (APA, 1987), which refers to persistent and excessive anxiety and worry, accompanied by motor tension and vigilance; (3) social phobia, which involves marked fear of social or performance situations in which embarrassment may occur; (4) panic disorder, which is characterized by the presence of panic attacks (i.e., discrete periods of intense fear), accompanied by persistent concern about their recurrence or their consequences; (5) obsessive-compulsive disorder, which is characterized by the occurrence of obsessions (i.e., intrusive ideas, thoughts, images, or impulses that cause marked anxiety or distress) and compulsions (i.e., repetitive behaviors or mental acts which serve to neutralize anxiety); (6) specific phobia, which is defined by marked and persistent anxiety provoked by exposure to a specific feared object or situation, often leading to avoidance behavior; and (7) acute stress disorder and post-traumatic stress disorder, which both involve the reexperiencing of an extremely traumatic event accompanied by increased arousal and avoidance of stimuli associated with the trauma.

In both research and clinical practice, self-report questionnaires for measuring childhood anxiety symptoms are frequently used. This type of measure is easy to administer, requires a minimum of time, and captures information about anxiety symptoms from the child's point of view (Strauss, 1993). The three most widely used instruments for this purpose have been the Revised Children's Manifest Anxiety Scale (RCMAS; Reynolds \& Richmond, 1978), the State-Trait Anxiety Inventory for Children (STAIC; Spielberger, 1973), and the Fear Survey Schedule for Children Revised (FSSC-R; Ollendick, 1983). All these instruments are age-downward versions of adult questionnaires.

The RCMAS is a widely used questionnaire with three anxiety-related subfactors: physiological manifestations of anxiety, worry and oversensitivity, and problems with fear/concentration (Reynolds \& Paget, 1983). The RCMAS is not a pure measure of childhood anxiety as it contains a number of mood items and items that have to do with attentional, impulsivity, and peer interaction problems. The STAIC consists of a state scale that measures present-state and situationlinked anxiety and a trait scale that addresses temporally stable anxiety across situations. The FSSC-R focuses primarily on phobic symptoms and taps fear of failure and criticism, fear of the unknown, fear of minor injury and small animals, fear of danger and death, and medical fears. Although all of these three measures have acceptable to good psychometric properties and provide useful information on childhood anxiety symptoms (e.g., Papay, Costello, Hedl, \& Spielberger, 
1975; Reynolds, 1982; Weems, Silverman, Saavedra, Pina, \& White Lupkin, 1999), their major shortcoming is that they are not linked to the anxiety categories that are listed in the DSM-IV (APA, 1994; see for a discussion Stallings \& March, 1995). As a result, the clinical utility of these measures is frequently questioned.

Over the past few years, a number of new questionnaires have been developed in an attempt to measure the various aspects of childhood anxiety in terms of the nosologic constructs that are currently employed by researchers and clinicians. In this context, three scales should be mentioned, namely the Multidimensional Anxiety Scale for Children (MASC; March, Parker, Sullivan, Stallings, \& Conners, 1997), the Screen for Child Anxiety Related Emotional Disorders (SCARED; Birmaher et al., 1997), and the Spence Children's Anxiety Scale (SCAS; Spence, 1998).

The MASC was constructed to assess four theoretically meaningful domains of childhood anxiety symptoms: affective, physical, cognitive, and behavioral. Items selected to represent these domains were subjected to factor analysis. Results, indeed, revealed four factors, yet the content of these factors deviated somewhat from the hypothesized anxiety domains. More precisely, the MASC seems to tap the following four dimensions of childhood anxiety: physical symptoms, social anxiety, separation anxiety, and harm avoidance. These psychometrically derived dimensions have been found consistently in normal and clinical samples (cf. March et al., 1997; March, Sullivan, \& Parker, 1999; March, Conners, et al., 1999). The psychometric properties of the MASC appear to be adequate with good internal consistency and test-retest stability (March et al., 1997; March, Sullivan, et al., 1999). Furthermore, there is some evidence for its concurrent and discriminant validity. For example, MASC scores correlate significantly with RCMAS scores (March et al., 1997) and the scale differentiates reasonably well between anxious children, normal children, and children with other types of psychopathology (see March, Sullivan, et al., 1999).

The SCARED and the SCAS are both questionnaires that are inspired by the anxiety disorders listed in the DSM-IV (APA, 1994). However, these questionnaires differ in important respects. The original version of the SCARED developed by Birmaher and colleagues (1997) measures symptoms of generalized anxiety disorder, separation anxiety disorder, social phobia, panic disorder, and school phobia. The SCAS covers a broader range of the anxiety disorders spectrum and assesses symptoms of generalized anxiety disorder, separation anxiety disorder, social phobia, panic disorder and agoraphobia, obsessive-compulsive disorder, and specific phobia represented by a subscale named "physical injury fears". Research has indicated that the psychometric properties of the SCARED and the SCAS are satisfactory. Both questionnaires possess adequate internal consistency and test-retest stability (e.g., Birmaher et al., 1997; Spence, 1998). Furthermore, the factor structure of both scales was found to be largely in keeping with the hypothesized categories of anxiety symptoms (Muris, Merckelbach, Schmidt, \& Mayer, 1999; Spence, 1997, 1998). Support has also been forthcoming for the concurrent validity of these scales. Thus, scores of the SCARED and SCAS correlate strongly with scores on traditional childhood anxiety measures (i.e., RCMAS, STAIC, and FSSC-R; Muris, Merckelbach, Van Brakel, Mayer, \& Van Dongen, 1998; Muris, Merckelbach, Mayer, et al., 1998). Finally, the SCARED and the SCAS possess adequate discriminant validity. More specifically, there is evidence to suggest that both questionnaires are able to differentiate between children with and without specific anxiety disorders (Birmaher et al., 1997; Birmaher et al., 1999; Muris, Merckelbach, Mayer, \& Prins, 2000; Spence, 1998). 
While previous studies have provided evidence for the reliability and validity of the previously mentioned childhood anxiety measures, to date no research has directly compared the psychometrics of traditional and new childhood anxiety scales in a systematic fashion. Such a comparison would be useful because its results may inform clinical practice and research matters (e.g., selection of research tools). The current study was conducted to address this issue. The psychometric properties of three traditional (i.e., RCMAS, STAIC, and FSSC-R) and three relatively new childhood anxiety measures (i.e., MASC, SCARED, and SCAS) were examined in a large sample of normal adolescents. First, the reliability (internal consistency) of the questionnaires was evaluated. Second, convergent validity was investigated by computing intercorrelations among the various scales. Third, divergent validity of the childhood anxiety measures was examined by relating them to a measure of depression.

\section{Method}

\subsection{Participants and procedure}

Five hundred and twenty one adolescents (240 boys and 281 girls; mean age=15.1 years, $\mathrm{SD}=2.0$, range 12-18 years) were recruited from a regular secondary school in Belgium. Participants completed a set of questionnaires (see below) in their classrooms. The teacher and a research assistant were present to provide clarification if necessary and to ensure confidential and independent responding. The Children's Depression Inventory (CDI; Kovacs, 1981) was always administered first. Next, anxiety scales (with traditional and new measures in an alternating sequence, e.g., RCMAS, SCARED, STAIC, MASC, FSSC-R, and SCAS) were administered. The order of traditional and new measures was counterbalanced across the various classrooms. Questionnaires were in Dutch which was the native language of all adolescents.

\subsection{Questionnaires}

\subsubsection{Traditional anxiety questionnaires}

The trait version of the STAIC contains 20 items that measure chronic symptoms of anxiety. The child/adolescent is asked to rate the frequency with which (s)he experiences anxiety symptoms such as "I am scared", "I feel troubled", and "I get a funny feeling in my stomach" using three-point scales: $1=$ almost never, $2=$ sometimes, and $3=$ often. The STAIC is considered to be a unidimensional measure. A total trait anxiety score can be calculated by summing the ratings for all items.

The RCMAS consists of 28 dichotomous (yes/no) items and also assesses the level of general anxiety in youths. Sample items are "I am afraid of a lot of things", "I am nervous", and "I often worry about something bad happening to me". Yes-responses are scored in the positive direction and summed to yield a total score. Three factor scores can be obtained (Reynolds \& Paget, 1983): physiological anxiety, worry/oversensitivity, and concentration (e.g., "It is hard for me to keep my mind on my school work").

The FSSC-R is an 80-item questionnaire that measures fearfulness. Children/adolescents are asked to indicate their level of fear of various stimuli and situations on a three-point scale 
( $1=$ none, $2=$ some, or $3=\mathrm{a}$ lot). Scores are summed to yield a total score. Factor analysis of the FSSC-R has revealed a five-factor solution: fear of failure and criticism, fear of the unknown, fear of animals/minor injuries, fear of danger and death, and medical fears. Studies have demonstrated that this factor structure can be generalized across children and adolescents in various western countries (Ollendick, 1983; Ollendick, King, \& Frary, 1989; Ollendick, Yule, \& Ollier, 1991).

\subsubsection{New anxiety questionnaires}

The MASC is a 39-item self-report instrument comprising four empirically-derived domains of childhood anxiety: physical symptoms (e.g., "My heart races or skips beats"), harm avoidance (e.g., "I stay away from things that upset me"), social anxiety (e.g., "I worry about what other people think of me"), and separation anxiety (e.g., "The idea of going away to camp scares me"). MASC items are scored on four-point scales $(0=$ never, $1=$ almost never, $2=$ sometimes, $3=0$ ften). A total score and subscale scores can be calculated by summing relevant items.

The SCARED is an inventory assessing anxiety disorder symptoms in children and adolescents. The scale consists of 41 items that can be allocated to five subscales. Four of them parallel anxiety disorders as classified in the DSM, viz. panic/somatic (e.g., "When frightened, my heart beats fast"), generalized anxiety (e.g., "I am a worrier"), separation anxiety (e.g., "I don't like being away from my family"), and social phobia (e.g., "I don't like to be with unfamilar people"). The fifth subscale is school phobia (e.g., "I am scared to go to school") which represents a common anxiety problem in youths. Children/adolescents are asked to rate the frequency with which they experience each symptom using three-point scales $(0=$ almost never, $1=$ sometimes, $2=$ often). SCARED total and subscale scores are obtained by summing relevant items.

The SCAS is a questionnaire measuring DSM-defined anxiety disorder symptoms in youths. The scale contains 38 items that can be allocated to the following six subscales: generalized anxiety (e.g., "I worry that something bad will happen"), separation anxiety (e.g., "I feel scared when I have to sleep on my own"), social phobia (e.g., "I feel afraid that I will make a fool of myself in front of people"), panic disorder/agoraphobia (e.g., "All of a sudden I feel really scared for no reason at all", "I am afraid of being in crowded places"), obsessive-compulsive disorder (e.g., "I have to think of special thoughts to stop bad things from happening"), and physicalinjury fears representing specific phobias (e.g., "I am scared of insects or spiders"). SCAS items are rated on four-point scales ( $0=$ never, $1=$ sometimes, $3=$ often, $4=$ always). SCAS total and subscale scores are computed by summing relevant items.

\subsection{Measure of depression}

The CDI is a commonly used self-report instrument to measure depression symptoms in children and adolescents. The scale consists of 27 items relating to sadness, self-blame, loss of appetite, insomnia, interpersonal relationships, and school adjustment. Sample items are "I am sad all the time" and "I feel like crying every day". CDI items are scored on three-point scales $(0=$ not true, $1=$ somewhat true, $2=$ very true). A total CDI score can be calculated by summing all item scores and varies between 0 (no depression symptoms) and 54 (all depression symptoms clearly present). 


\subsection{Statistical analysis}

The Statistical Package for Social Sciences (SPSS) was employed to compute descriptive statistics, reliability coefficients, $t$-tests, analyses of variance, and correlations. To examine the divergent validity of the anxiety questionnaires, magnitudes of correlations were compared using the method as described by Meng, Rosenthal, and Rubin (1992).

\section{Results}

\subsection{Reliability}

Reliability coefficients (Cronbach's alphas) for the various questionnaires are presented in Table 1. As can be seen, most scales were reliable in terms of internal consistency. That is, alpha values were generally well above 0.60 . The only notable exception was the SCAS subscale of physical injury fears which had an $\alpha$ of 0.54 (this subscale contains only 5 items). Due to item length, the total scores produced higher internal consistency estimates than the factor subscale scores.

It should be noted that mean scores on the various anxiety measures were rather low (see Table 1). That is, the mean total scores on the questionnaires as obtained in the current sample were well below the normative means as provided in previous studies (e.g., Ollendick, 1983; March, Sullivan et al., 1999; Muris, Schmidt, \& Merckelbach, 2000; Reynolds \& Paget, 1983; Spielberger, 1973).

Table 1 shows mean scores of boys and girls on various measures. Except for RCMAS concentration and SCARED school phobia, girls exhibited significantly higher levels of anxiety symptoms than boys, which is, of course, in line with a vast amount of previous research (see for a review, Craske, 1997). Correlations between age and anxiety scores were generally weak. In fact, only one of 29 correlation coefficients attained statistical significance: the older adolescents were, the lower their scores on the MASC separation anxiety subscale $(r=-0.14, P<0.001)$. Although significant, this relationship accounted for only $2 \%$ of the variance.

\subsection{Convergent validity}

\subsubsection{Correlations among traditional anxiety questionnaires}

Table 2 presents correlations (corrected for gender and age) among STAIC, RCMAS, and FSSC-R. Note that all correlations were positive and significant. Most importantly, the total scores of STAIC and RCMAS were highly correlated: $r=0.88$, whereas the total scores of STAIC and RCMAS were moderately connected to FSSC-R (both $r s=0.63$ ). These results indicate that STAIC and RCMAS tap highly allied constructs, while the FSSC-R seems to measure a somewhat different aspect of anxiety (i.e., specific fears, phobias).

\subsubsection{Correlations among new anxiety questionnaires}

The correlations (corrected for gender and age) among MASC, SCARED, and SCAS are displayed in Table 3. As can be seen, the total scores of these questionnaires were substantially intercorrelated with $r$ s ranging between 0.71 (MASC and SCAS) and 0.84 (SCARED and SCAS). 
Table 1

Means (standard deviations), gender differences, relationship with age, and reliability coefficients (Cronbach's alphas) for the childhood anxiety questionnaires ${ }^{\mathrm{a}}$

\begin{tabular}{|c|c|c|c|c|}
\hline & $\begin{array}{l}\text { Total group } \\
(N=521)\end{array}$ & $\begin{array}{l}\text { Boys } \\
(n=240)\end{array}$ & $\begin{array}{l}\text { Girls } \\
(n=281)\end{array}$ & $\alpha$ \\
\hline \multicolumn{5}{|l|}{ STAIC } \\
\hline Total score & $30.3(7.9)$ & $28.2(7.3)_{\mathrm{a}}$ & $32.1(7.9)_{\mathrm{b}}$ & 0.91 \\
\hline \multicolumn{5}{|l|}{$R C M A S$} \\
\hline Total score & $7.0(6.0)$ & $5.7(5.6)_{\mathrm{a}}$ & $8.1(6.1)_{\mathrm{b}}$ & 0.89 \\
\hline Physiological anxiety & $2.2(2.1)$ & $1.8(1.9)_{\mathrm{a}}$ & $2.6(2.1)_{\mathrm{b}}$ & 0.69 \\
\hline Worry/oversensitivity & $3.1(2.9)$ & $2.3(2.6)_{\mathrm{a}}$ & $3.8(3.1)_{\mathrm{b}}$ & 0.84 \\
\hline Concentration & $1.7(1.8)$ & $1.6(1.8)_{\mathrm{a}}$ & $1.8(1.8)_{\mathrm{a}}$ & 0.72 \\
\hline \multicolumn{5}{|l|}{$F S S C-R$} \\
\hline Total score & $98.0(20.6)$ & $89.3(17.2)_{\mathrm{a}}$ & $105.4(20.4)_{\mathrm{b}}$ & 0.96 \\
\hline Fear of failure and criticism & $31.1(7.4)$ & $29.2(6.6)_{a}$ & $32.7(7.7)_{b}$ & 0.91 \\
\hline Fear of the unknown & $20.1(5.1)$ & $18.0(3.8)_{\mathrm{a}}$ & $21.9(5.4)_{\mathrm{b}}$ & 0.87 \\
\hline $\begin{array}{l}\text { Fear of animals/minor } \\
\text { injuries }\end{array}$ & $21.3(5.1)$ & $19.1(3.8)_{\mathrm{a}}$ & $23.2(5.3)_{\mathrm{b}}$ & 0.85 \\
\hline Fear of danger and death & $20.2(5.5)$ & $18.0(5.0)_{\mathrm{a}}$ & $22.1(5.3)_{\mathrm{b}}$ & 0.89 \\
\hline Medical fears & $5.3(1.6)$ & $5.0(1.4)_{\mathrm{a}}$ & $5.5(1.7)_{\mathrm{b}}$ & 0.65 \\
\hline \multicolumn{5}{|l|}{$M A S C$} \\
\hline Total score & $38.0(18.8)$ & $32.0(18.3)_{\mathrm{a}}$ & $43.2(17.7)_{\mathrm{b}}$ & 0.93 \\
\hline Physical symptoms & $8.7(7.2)$ & $6.9(6.4)_{\mathrm{a}}$ & $10.3(7.4)_{\mathrm{b}}$ & 0.89 \\
\hline Harm avoidance & $14.3(5.4)$ & $13.2(5.8)_{\mathrm{a}}$ & $15.2(4.7)_{\mathrm{b}}$ & 0.79 \\
\hline Social anxiety & $9.7(6.9)$ & $7.7(6.7)_{\mathrm{a}}$ & $11.4(6.6)_{\mathrm{b}}$ & 0.90 \\
\hline Separation anxiety & $5.4(4.0)$ & $4.3(3.6)_{\mathrm{a}}$ & $6.3(4.0)_{\mathrm{b}}$ & 0.65 \\
\hline \multicolumn{5}{|l|}{ SCARED } \\
\hline Total score & $16.1(12.6)$ & $12.6(11.3)_{\mathrm{a}}$ & $19.1(12.9)_{\mathrm{b}}$ & 0.91 \\
\hline Panic/somatic & $2.8(3.9)$ & $2.1(3.0)_{a}$ & $3.4(4.4)_{\mathrm{b}}$ & 0.88 \\
\hline Generalized anxiety & $4.9(4.3)$ & $3.5(3.8)_{\mathrm{a}}$ & $6.0(4.3)_{\mathrm{b}}$ & 0.88 \\
\hline Separation anxiety & $2.4(2.5)$ & $1.8(2.2)_{\mathrm{a}}$ & $2.9(2.7)_{\mathrm{b}}$ & 0.75 \\
\hline Social phobia & $4.8(3.7)$ & $4.2(3.7)_{\mathrm{a}}$ & $5.3(3.5)_{\mathrm{b}}$ & 0.89 \\
\hline School phobia & $1.2(1.6)$ & $1.0(1.5)_{\mathrm{a}}$ & $1.4(1.7)_{\mathrm{a}}$ & 0.76 \\
\hline \multicolumn{5}{|l|}{$S C A S$} \\
\hline Total score & $16.9(13.1)$ & $12.7(10.4)_{a}$ & $20.4(14.0)_{\mathrm{b}}$ & 0.93 \\
\hline Panic/agoraphobia & $2.2(3.3)$ & $1.4(2.3)_{\mathrm{a}}$ & $2.9(3.8)_{\mathrm{b}}$ & 0.83 \\
\hline Separation anxiety & $2.0(2.0)$ & $1.3(1.6)_{\mathrm{a}}$ & $2.5(2.2)_{\mathrm{b}}$ & 0.62 \\
\hline Social phobia & $3.6(3.0)$ & $2.8(2.7)_{a}$ & $4.3(3.1)_{\mathrm{b}}$ & 0.75 \\
\hline Physical injury fears & $2.3(2.2)$ & $1.4(1.9)_{\mathrm{a}}$ & $3.0(2.2)_{\mathrm{b}}$ & 0.54 \\
\hline $\begin{array}{l}\text { Obsessive-compulsive } \\
\text { disorder }\end{array}$ & $2.9(3.0)$ & $2.6(2.7)_{\mathrm{a}}$ & $3.2(3.1)_{\mathrm{b}}$ & 0.76 \\
\hline Generalized anxiety & $3.9(3.0)$ & $3.0(2.5)_{\mathrm{a}}$ & $4.6(3.2)_{\mathrm{b}}$ & 0.81 \\
\hline
\end{tabular}

a Notes: STAIC - trait version of the Spielberger State-Trait Anxiety Inventory; RCMAS - Revised Children's Manifest Anxiety Scale; FSSC-R — Fear Survey Schedule for Children - Revised; MASC — Multidimensional Anxiety Scale for Children; SCARED - Screen for Child Anxiety Related Emotional Disorders; SCAS — Spence Children's Anxiety Scale. Means in the same row that do not share the same subscripts differ at $P<0.001$. 


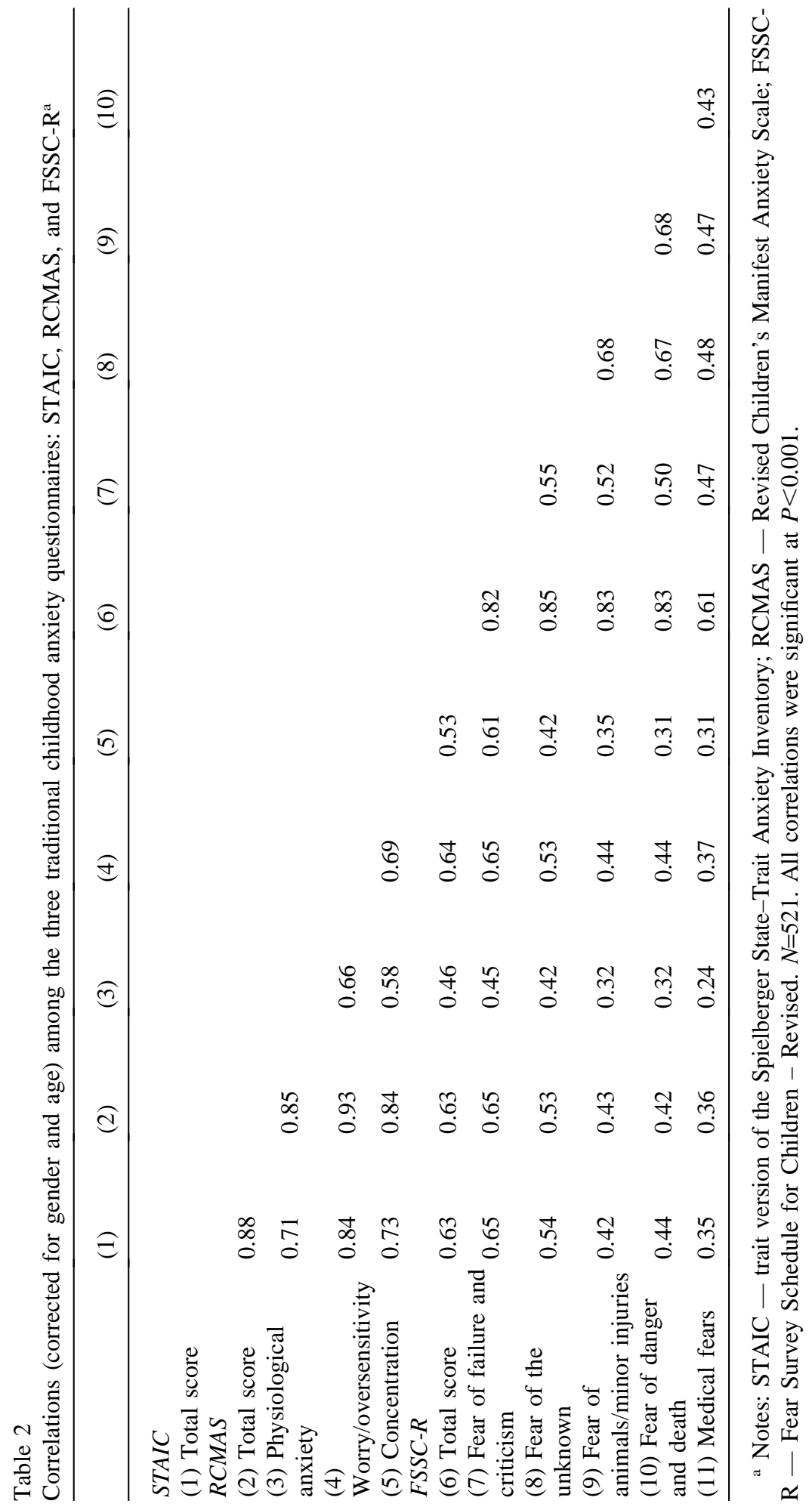


P. Muris et al. / Behaviour Research and Therapy 40 (2002) 753-772

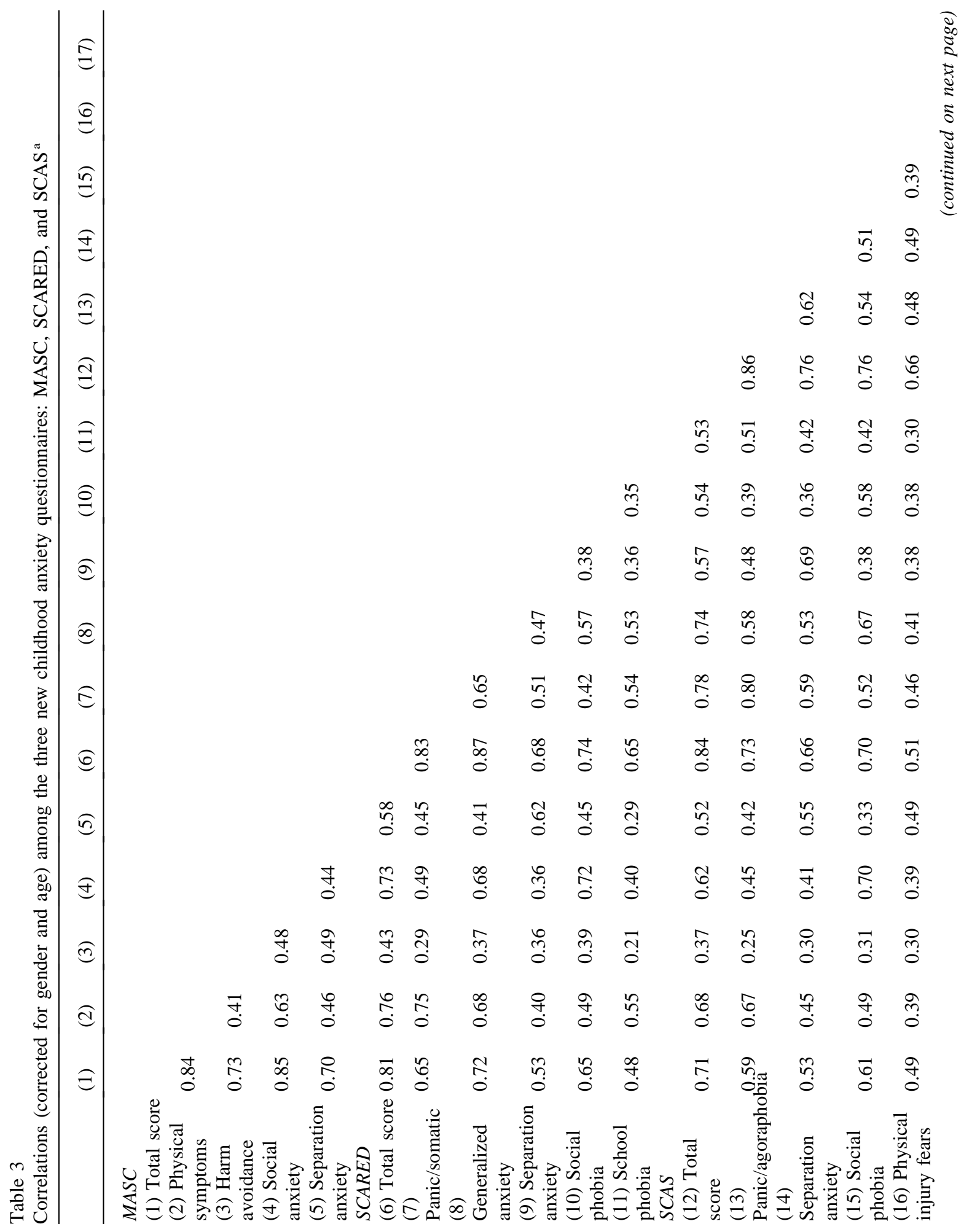




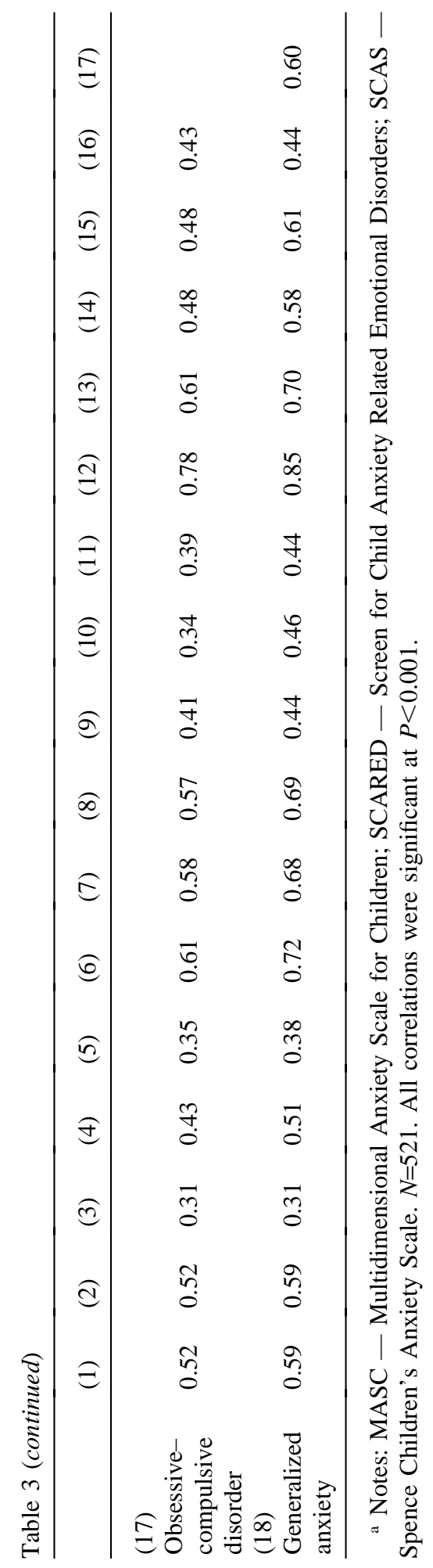


Furthermore, correlations among the subscales of the various questionnaires followed the expected pattern. That is, the most substantial associations were found between subscales that intend to measure the same type of anxiety symtoms. Thus, substantial correlations emerged between MASC physical symptoms, SCARED panic/somatic, and SCAS panic/agoraphobia ( $r$ s between 0.67 and 0.80 ), between MASC social anxiety and the social phobia scales of the SCARED and SCAS ( $r$ s between 0.58 and 0.72 ), between the separation anxiety scales of the three questionnaires ( $r$ s between 0.55 and 0.69 ), and between the generalized anxiety scales of SCARED and $\operatorname{SCAS}(r=0.69)$.

\subsubsection{Correlations between MASC and traditional anxiety questionnaires}

Table 4 shows that the total score of the MASC was strongly related to the total scores of the STAIC and the RCMAS ( $r$ s of 0.79 and 0.76, respectively) and, to a lesser extent, to the total FSSC-R score $(r=0.63)$. Furthermore, MASC subscales were associated in a theoretically meaningful way with subscales of traditional measures. That is, substantial correlations were found between MASC physical symptoms and the physiological subscale of RCMAS $(r=0.70)$, between MASC social anxiety and RCMAS subscales of worry/oversensitivity and concentration ( $r$ s were 0.71 and 0.66 ) and the FSSC-R subscale fear of failure and criticism (with items such as "Looking foolish" and "Being criticized by others"; $r=0.65$ ), and between MASC separation anxiety and

Table 4

Correlations (corrected for gender and age) between MASC and traditional anxiety questionnaires ${ }^{\mathrm{a}}$

\begin{tabular}{|c|c|c|c|c|c|}
\hline & \multicolumn{5}{|l|}{ MASC } \\
\hline & Total score & $\begin{array}{l}\text { Physical } \\
\text { symptoms }\end{array}$ & Harm avoidance & Social anxiety & $\begin{array}{l}\text { Separation } \\
\text { anxiety }\end{array}$ \\
\hline \multicolumn{6}{|l|}{ STAIC } \\
\hline $\begin{array}{l}\text { Total score } \\
\text { RCMAS }\end{array}$ & 0.79 & 0.76 & 0.41 & 0.72 & 0.50 \\
\hline Total score & 0.76 & 0.75 & 0.37 & 0.72 & 0.48 \\
\hline Physiological anxiety & 0.60 & 0.70 & 0.26 & 0.49 & 0.40 \\
\hline Worry/oversensitivity & 0.74 & 0.68 & 0.40 & 0.71 & 0.46 \\
\hline $\begin{array}{l}\text { Concentration } \\
F S S C-R\end{array}$ & 0.64 & 0.61 & 0.29 & 0.66 & 0.37 \\
\hline Total score & 0.63 & 0.50 & 0.40 & 0.56 & 0.57 \\
\hline $\begin{array}{l}\text { Fear of failure and } \\
\text { criticism }\end{array}$ & 0.61 & 0.51 & 0.32 & 0.65 & 0.38 \\
\hline Fear of the unknown & 0.55 & 0.44 & 0.34 & 0.42 & 0.60 \\
\hline $\begin{array}{l}\text { Fear of animals/minor } \\
\text { injuries }\end{array}$ & 0.49 & 0.36 & 0.34 & 0.38 & 0.51 \\
\hline $\begin{array}{l}\text { Fear of danger and } \\
\text { death }\end{array}$ & 0.44 & 0.32 & 0.36 & 0.31 & 0.45 \\
\hline Medical fears & 0.32 & 0.25 & 0.18 & 0.29 & 0.31 \\
\hline
\end{tabular}

a Notes: MASC — Multidimensional Anxiety Scale for Children; STAIC — trait version of the Spielberger StateTrait Anxiety Inventory; RCMAS - Revised Children's Manifest Anxiety Scale; FSSC-R — Fear Survey Schedule for Children - Revised. $N=521$. All correlations were significant at $P<0.001$. 
FSSC-R fear of the unknown (with items such as "Being alone" and "Nightmares"). Finally, modest correlations were found between MASC harm/avoidance and traditional anxiety questionnaires.

\subsubsection{Correlations between SCARED and traditional anxiety questionnaires}

As can be seen in Table 5, the total SCARED score was strongly associated with both STAIC and the RCMAS total scores ( $r$ s were 0.87 and 0.85 , respectively) and somewhat less but still substantial with the FSSC-R total score $(r=0.72)$. In addition, SCARED subscales generally displayed the expected pattern of intercorrelations with subscales of traditional anxiety scales. For example, robust associations emerged between SCARED panic/somatic and RCMAS physiological $(r=0.68)$, between SCARED generalized anxiety and RCMAS worry/oversensitivity $(r=0.82)$, between SCARED separation anxiety and FSSC-R fear of the unknown $(r=0.58)$, between SCARED social phobia and RCMAS worry/oversensitivity and concentration ( $r$ s were 0.55 and $0.50)$ and FSSC-R fear of failure and criticism $(r=0.57)$, and between SCARED school phobia and RCMAS worry/oversensitivity and concentration ( $r$ s were 0.53 and 0.51 ).

\subsubsection{Correlations between SCAS and traditional anxiety questionnaires}

As shown in Table 6, the SCAS total score was substantially connected to STAIC, RCMAS, and FSSC-R total scores ( $r$ s were 0.79, 0.76, and 0.76, respectively). Furthermore, correlations

Table 5

Correlations (corrected for gender and age) between SCARED and traditional anxiety questionnaires ${ }^{\mathrm{a}}$

\begin{tabular}{|c|c|c|c|c|c|c|}
\hline & \multicolumn{6}{|l|}{ SCARED } \\
\hline & Total score & Panic/somatic & $\begin{array}{l}\text { Generalized } \\
\text { anxiety }\end{array}$ & $\begin{array}{l}\text { Separation } \\
\text { anxiety }\end{array}$ & Social phobia & School phobia \\
\hline \multicolumn{7}{|l|}{ STAIC } \\
\hline $\begin{array}{l}\text { Total score } \\
\text { RCMAS }\end{array}$ & 0.87 & 0.73 & 0.84 & 0.53 & 0.59 & 0.57 \\
\hline Total score & 0.85 & 0.73 & 0.83 & 0.50 & 0.57 & 0.58 \\
\hline Physiological anxiety & 0.68 & 0.68 & 0.61 & 0.40 & 0.42 & 0.48 \\
\hline Worry/oversensitivity & 0.83 & 0.64 & 0.82 & 0.52 & 0.55 & 0.53 \\
\hline $\begin{array}{l}\text { Concentration } \\
F S S C-R\end{array}$ & 0.71 & 0.58 & 0.71 & 0.37 & 0.50 & 0.51 \\
\hline Total score & 0.72 & 0.60 & 0.61 & 0.57 & 0.54 & 0.42 \\
\hline $\begin{array}{l}\text { Fear of failure and } \\
\text { criticism }\end{array}$ & 0.72 & 0.55 & 0.67 & 0.44 & 0.57 & 0.44 \\
\hline Fear of the unknown & 0.64 & 0.56 & 0.49 & 0.58 & 0.44 & 0.36 \\
\hline $\begin{array}{l}\text { Fear of animals/minor } \\
\text { injuries }\end{array}$ & 0.51 & 0.43 & 0.40 & 0.41 & 0.40 & 0.26 \\
\hline $\begin{array}{l}\text { Fear of danger and } \\
\text { death }\end{array}$ & 0.50 & 0.45 & 0.39 & 0.49 & 0.33 & 0.26 \\
\hline Medical fears & 0.40 & 0.32 & 0.34 & 0.31 & 0.28 & 0.28 \\
\hline
\end{tabular}

a Notes: SCARED — Screen for Child Anxiety Related Emotional Disorders; STAIC — trait version of the Spielberger State-Trait Anxiety Inventory; RCMAS - Revised Children's Manifest Anxiety Scale; FSSC-R — Fear Survey Schedule for Children - Revised. $N=521$. All correlations were significant at $P<0.001$. 
P. Muris et al. / Behaviour Research and Therapy 40 (2002) 753-772

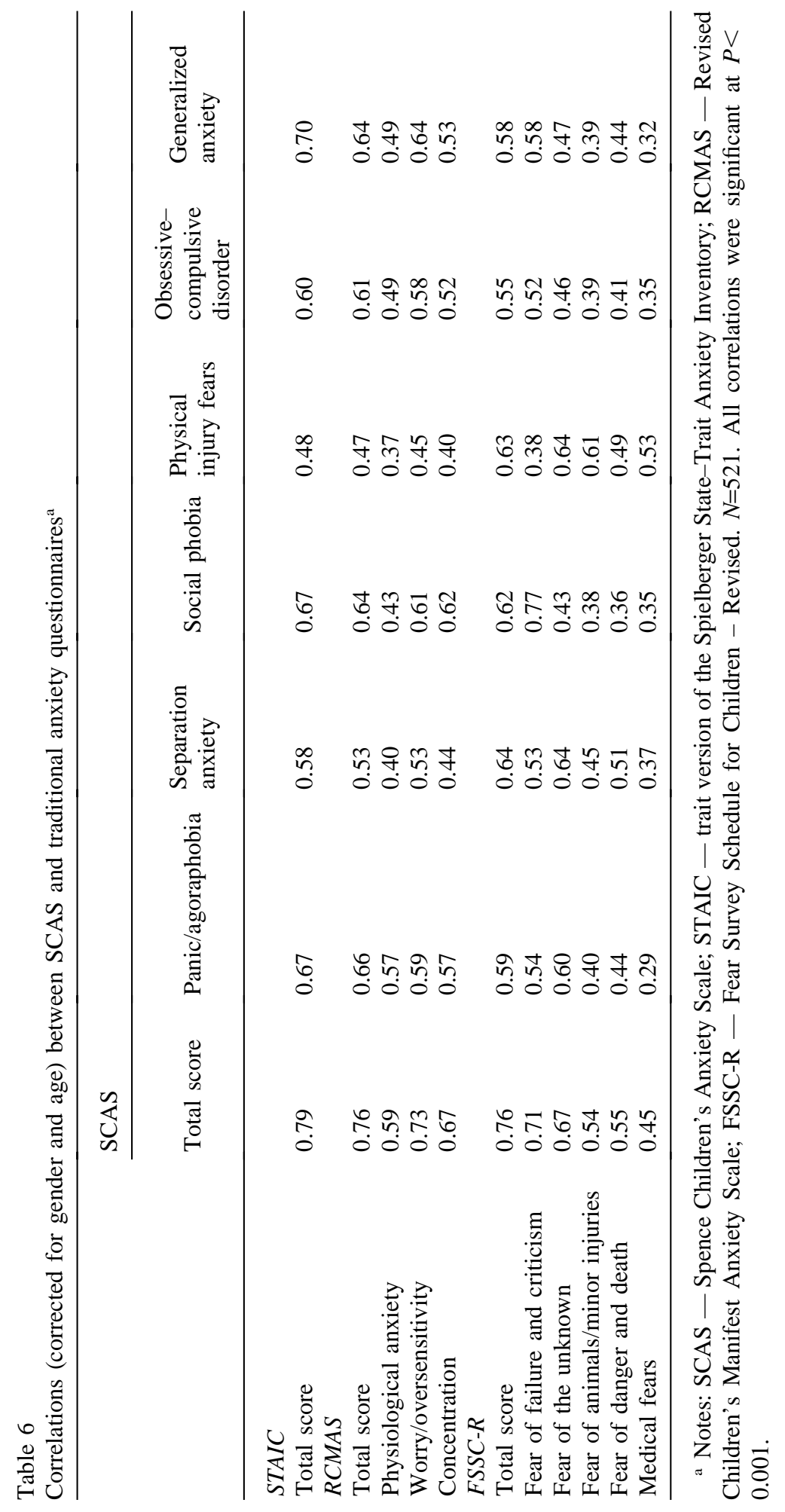


among subscales of SCAS and traditional measures generally showed the predicted pattern. That is, relatively strong correlations were found between SCAS panic/agoraphobia and RCMAS physiological anxiety ( $r=0.57$, although this SCAS subscale was also closely linked to RCMAS worry/oversensitivity and concentration and FSSC-R fear of the unknown), between SCAS separation anxiety and FSSC-R fear of the unknown $(r=0.64)$, between SCAS social phobia and RCMAS worry/oversensitivity and concentration ( $r$ s were 0.61 and 0.62 ) and FSSC-R fear of failure and criticism $(r=0.77)$, between SCAS physical injury fears and FSSC-R fear of the unknown and fear of animals/minor injuries ( $r$ s were 0.64 and 0.61 , respectively), between SCAS obsessive-compulsive disorder and RCMAS worry/oversensitivity $(r=0.58)$, and between SCAS generalized anxiety and RCMAS worry/oversensitivity ( $r=0.64)$.

\subsection{Divergent validity}

Correlations between anxiety questionnaires and CDI are displayed in Table 7. As can be seen, the total scores of STAIC, RCMAS, SCARED, and SCAS all correlated in the 0.70 range with the CDI, indicating that there is considerable overlap between anxiety as indexed by these measures and depression. The FSSC-R and the MASC were less strongly correlated to the CDI ( $r$ s were 0.50 and 0.60 , respectively). Furthermore, it was found that those subscales which tap symptoms of the more severe childhood anxiety problems (panic disorder, generalized anxiety disorder, and social phobia) had the highest correlations with the CDI.

To examine the divergent validity of the childhood anxiety questionnaires in more detail, Meng et al.'s (1992) method was used to compare the correlations among anxiety scales with those between anxiety scales and depression. Twenty-two out of 30 comparisons revealed that the connection among anxiety questionnaires was significantly larger than that between the anxiety questionnaire and the depression scale (all $Z s>2.0, P s<0.05$ ). Thus, the majority of the anxiety scales was more substantially connected to other anxiety measures than to an index of depression. Interestingly, the connections between STAIC and RCMAS, on the one hand, and FSSC-R, on the other hand, were significantly smaller than the correlations between these anxiety scales and depression (both $Z \mathrm{~s}=3.9, P \mathrm{~s}<0.001$ ) indicating that STAIC and RCMAS were more closely tied to a measure of depression than to a measure of fear.

\section{Discussion}

The current study systematically compared the psychometric properties of three traditional (STAIC, RCMAS, and FSSC-R) and three new childhood anxiety scales (MASC, SCARED, and SCAS). The main results can be catalogued as follows. First, childhood anxiety scales were generally found to be reliable in terms of internal consistency. Second, evidence was obtained for the convergent validity of various anxiety questionnaires. That is, anxiety questionnaire scores correlated substantially with each other. In particular, strong associations were found between the total STAIC and RCMAS scores $(r=0.88)$, the total SCARED and SCAS scores $(r=0.84)$, and among subscales that intend to measure a specific type of anxiety symptoms (e.g., physical/panic symptoms, symptoms of worry, and symptoms of social anxiety). Third, childhood anxiety questionnaires were substantially connected to an index of depression (i.e., the CDI; with $r$ s between 0.50 
Table 7

Correlations (corrected for gender and age) between anxiety questionnaires and a scale of depression ${ }^{\mathrm{a}}$

\begin{tabular}{|c|c|}
\hline & CDI \\
\hline \multicolumn{2}{|l|}{ STAIC } \\
\hline Total score & 0.74 \\
\hline \multicolumn{2}{|l|}{ RCMAS } \\
\hline Total score & 0.74 \\
\hline Physiological anxiety & 0.61 \\
\hline Worry/oversensitivity & 0.66 \\
\hline Concentration & 0.69 \\
\hline \multicolumn{2}{|l|}{$F S S C-R$} \\
\hline Total score & 0.50 \\
\hline Fear of failure and criticism & 0.58 \\
\hline Fear of the unknown & 0.40 \\
\hline Fear of animals/minor injuries & 0.29 \\
\hline Fear of danger and death & 0.30 \\
\hline Medical fears & 0.30 \\
\hline \multicolumn{2}{|l|}{$M A S C$} \\
\hline Total score & 0.60 \\
\hline Physical symptoms & 0.66 \\
\hline Harm avoidance & 0.18 \\
\hline Social anxiety & 0.59 \\
\hline Separation anxiety & 0.33 \\
\hline \multicolumn{2}{|l|}{ SCARED } \\
\hline Total score & 0.71 \\
\hline Panic/somatic & 0.65 \\
\hline Generalized anxiety & 0.69 \\
\hline Separation anxiety & 0.37 \\
\hline Social phobia & 0.43 \\
\hline School phobia & 0.53 \\
\hline \multicolumn{2}{|l|}{$S C A S$} \\
\hline Total score & 0.72 \\
\hline Panic/agoraphobia & 0.66 \\
\hline Separation anxiety & 0.51 \\
\hline Social phobia & 0.60 \\
\hline Physical injury fears & 0.39 \\
\hline Obsessive-compulsive disorder & 0.57 \\
\hline Generalized anxiety & 0.60 \\
\hline
\end{tabular}

a Notes: CDI - Children's Depression Inventory; STAIC - trait version of the Spielberger State-Trait Anxiety Inventory; RCMAS — Revised Children's Manifest Anxiety Scale; FSSC-R - Fear Survey Schedule for Children Revised; MASC - Multidimensional Anxiety Scale for Children; SCARED - Screen for Child Anxiety Related Emotional Disorders; SCAS - Spence Children's Anxiety Scale. N=521. All correlations significant at $P<0.001$.

and 0.74). However, it should be added that the majority of the correlations among the anxiety questionnaires were (significantly) higher than those between anxiety scales and the depression measure. This, of course, underlines the divergent validity of the childhood anxiety measures.

The current findings demonstrate that childhood anxiety scales generally have good internal consistency. Only the physical-injury subscale of the SCAS had a Cronbach's alpha that was 
insufficient, a finding that makes sense when one realizes that this scale consists of only 5 items measuring a rather heterogeneous set of fears (fear of insects and spiders, dogs, the dark, doctors and dentists, and high places or elevators; see for a similar finding, Muris, Schmidt, \& Merckelbach, 2000).

The present data are largely consistent with previous studies that examined the relationships among traditional and new childhood anxiety questionnaires (e.g., Reynolds, 1980; March et al., 1997; Muris, Gadet, Moulaert, \& Merckelbach, 1998; Muris, Schmidt, et al., 2000; Muris \& Steerneman, 2001; Muris, Merckelbach, Mayer, et al., 1998; Muris, Merckelbach, Van Brakel, \& Mayer, 1999; Ollendick, 1983; Ollendick et al., 1991; Spence, 1998). With respect to the correlations among these measures, a number of remarks are in order. To begin with, the data show that the STAIC and the RCMAS are strongly allied questionnaires that both seem to tap general levels of anxiety (see for a discussion, Stallings \& March, 1995). A similar conclusion can be drawn with respect to the relationship between SCARED and SCAS, two scales that both intend to assess symptoms of DSM-defined anxiety disorders.

Secondly, though correlations between subscales that intend to tap discrete types of anxiety symptoms were substantial, one could maintain that they were not extremely robust. For example, SCARED generalized anxiety disorder correlated 0.69 with its SCAS counterpart, thus sharing only $47.6 \%$ of the variance. This finding may, in part, be due to measurement errors of most scales (cf. Cronbach's alpha values were generally between 0.60 and 0.90 ). Otherwise, there are some differences with regard to the content of subscales, even of subscales that attempt to tap symptoms of one and the same anxiety disorder. For instance, whereas items of the generalized anxiety disorder subscale of the SCARED all pertain to symptoms of worry, half of the items of the pertinent subscale of the SCAS are concerned with physical symptoms (e.g., "When I have a problem, my heart beats really fast"). Such differences in content have to do with the fact that some questionnaires (in this example: the SCARED) mainly intend to tap the key feature of an anxiety disorder, while other scales also try to cover secondary DSM-criteria (in this example: the SCAS).

Thirdly, when examining the intercorrelations among childhood anxiety questionnaires in more detail, one has to conclude that there were two scales that deviated to some extent from the other measures. The first is the FSSC-R which is generally considered to be a measure of specific fears and phobias (see Stallings \& March, 1995). Several authors have argued that specific fear is different from anxiety although both constructs seem to be part of a higher-order category of emotional distress called "negative affectivity" (e.g., Barlow, Chorpita, \& Turovsky, 1996; Chorpita, Albano, \& Barlow, 1998; see also below). Germane to this issue is a study by Ollendick et al. (1991) who conducted a factor analysis on the combined items of the FSSC-R, the RCMAS, and the CDI. Evidence was obtained for the presence of separate fear factors (comprising almost exclusively items from the FSSC-R) besides other factors tapping symptoms of anxiety and depression. The second scale in this category is the harm-avoidance subscale of the MASC. With items such as "I keep my eyes open for danger", "I check things out first", "I stay away from things that upset me", this scale seems to tap quite a unique aspect of childhood anxiety symptoms which is not assessed by any of the other measures.

In keeping with previous studies (e.g., Dong, Yang, \& Ollendick, 1994; Muris, Merckelbach, Van Brakel, et al., 1998; Ollendick et al., 1991), substantial associations were observed between childhood anxiety measures and depression (as measured by the CDI). In the past, this observation 
has led researchers to conclude that anxiety and depression are not really distinguishable constructs in children and adolescents (Finch, Lipovsky, \& Casat, 1989; see for a discussion of this topic, King, Ollendick, \& Gullone, 1991). However, in more recent years, evidence has accumulated that anxiety and depression are related but distinct phenomena each characterized by a typical constellation of emotions. More specifically, anxiety seems to be associated with high negative affect, high physiological arousal, and normal levels of positive affect, whereas depression is characterized by high negative affect, normal physiological arousal, and low levels of positive affect (Chorpita, Daleiden, Moffitt, Yim, \& Umemoto, 2000; Daleiden, Chorpita, \& $\mathrm{Lu}, 2000)$. These observations give rise to a number of alternative explanations for the high correlations between anxiety and depression. A first explanation is that anxiety and depression are distinct conditions that frequently co-occur. This comorbidity of anxiety and depression may be due to the fact that similar etiological mechanisms are involved in both phenomena (e.g., Biederman, Rosenbaum, Chaloff, \& Kagan, 1995) or that one disorder increases the risk for the other (e.g., Cole, Peeke, Martin, Truglio, \& Seroczynski, 1998). A second explanation views comorbidity as an artifact of the crude assessment of anxiety and depression. More precisely, the questionnaires may simply not be sensitive enough to differentiate between anxiety and depression. Inspection of the items of the various scales, indeed, reveals that anxiety questionnaires, in particular traditional scales such as the STAIC and the RCMAS, show a considerable overlap in content with CDI items. Although the new measures seem to have improved in this respect (see also Chorpita, Yim, Moffitt, Umemoto, \& Francis, 2000), their correlation with depression is still substantial. This finding in combination with the finding that depression scores had their strongest correlations with symptoms of the more severe anxiety disorders (e.g., generalized anxiety disorder, social phobia), suggest that the first alternative explanation may be closer to the truth than the second explanation.

Two additional findings of the present study require some comment. First of all, marked gender differences were found for most anxiety scales. This result accords well with earlier research showing that girls generally exhibit higher levels of anxiety symptoms than boys (see Craske, 1997; Bernstein et al., 1996). Second, while previous studies generally found a decline of anxiety with increasing age, such an age effect was absent in the current sample. It should be mentioned, though, that these earlier studies relied on child samples with a broader age range (e.g., Muris, Schmidt, et al., 2000). The present study was merely concerned with adolescents aged 12-18 years and it may well be that anxiety symptoms are relatively stable in this age range.

The results of the current study are subject to a number of limitations. To begin with, the study relied solely on self-reports of adolescents. Although adolescents (and children) are generally regarded as the most important informant in the case of emotional problems such as anxiety, collateral information from e.g., parents or teachers could have provided additional information. Further, the participants in the present sample displayed relatively low anxiety scores on all questionnaires (compared to normative means provided in previous studies) and so it is questionable whether the current results can be generalized to other samples. Meanwhile, it should be noted that, despite these low scores, the predicted pattern of results was generally found. Finally, the study only included adolescents aged 12-18 years. It remains to be seen to what extent the present conclusions can be generalized to younger children.

In their comprehensive review of childhood anxiety measures, Stallings and March (1995, p. 127) noted that "Ideally, instruments to assess anxiety in young persons should (1) provide reliable 
and valid ascertainment of symptoms across multiple symptom domains; (2) discriminate symptom clusters; (3) evaluate severity; (4) incorporate and reconcile multiple observations, such as parent and child ratings; and (5) should be sensitive to treatment-induced change in symptoms". The literature on childhood anxiety scales (including the current study) shows that none of the scales meet all these criteria. For example, the STAIC is unidimensional and hence does not tap various symptom domains. Further, although for most measures, parent versions seem to be available, there are few studies that have thoroughly examined the psychometrics of these scales (e.g., Birmaher et al., 1997; March et al., 1997). Finally, whereas traditional scales have proven their sensitivity for treatment effects (e.g., Kendall, 1994), this information is still lacking for most of the newly developed questionnaires (but see Muris, Merckelbach, Gadet, Moulaert, \& Tierney, 1999).

To recap, the results of the current study show that the psychometric qualities of childhood anxiety questionnaires are satisfactory and that this is true for traditional as well as new scales. Therefore, the question arises whether the new childhood anxiety measures have any incremental value above the traditional scales. One important advantage of the newly developed instruments (i.e., SCARED, SCAS, and MASC) is that they are more closely connected to current diagnostic systems such as the DSM and thus facilitate communication about anxiety problems in children and adolescents (Chorpita, Yim, et al., 2000).

\section{References}

American Academy of Child and Adolescent Psychiatry (1997). Practice parameters for the assessment and treatment of children and adolescents with anxiety disorders. Journal of the American Academy of Child and Adolescent Psychiatry, 36(Suppl.), 69S-84S.

American Psychiatric Association (1987). Diagnostic and statistical manual of mental disorders (3rd ed. — revised). Washington, DC: American Psychiatric Association.

American Psychiatric Association (1994). Diagnostic and statistical manual of mental disorders (4th ed.). Washington, DC: American Psychiatric Association.

Barlow, D. H., Chorpita, B. F., \& Turovsky, J. (1996). Fear, panic, anxiety, and the disorders of emotion. In D. A. Hope, Nebraska symposium on motivation: perspectives on anxiety, panic, and fear, (Vol. 43). (pp. 251-328). Lincoln, NE: University of Nebraska Press.

Bernstein, G. A., Borchardt, C. M., \& Perwien, A. R. (1996). Anxiety disorders in children and adolescents: A review of the past 10 years. Journal of the American Academy of Child and Adolescent Psychiatry, 35, $1110-1119$.

Biederman, J., Rosenbaum, J. F., Chaloff, J., \& Kagan, J. (1995). Behavioral inhibition as a risk factor for anxiety disorders. In J. S. March, Anxiety disorders in children and adolescents (pp. 61-81). New York: Guilford Press.

Birmaher, B., Khetarpal, S., Brent, D., Cully, M., Balach, L., Kaufman, J., \& McKenzie Neer, S. (1997). The Screen for Child Anxiety Related Emotional Disorders (SCARED): Scale construction and psychometric characteristics. Journal of the American Academy of Child and Adolescent Psychiatry, 36, 545-553.

Birmaher, B., Brent, D., Chiappetta, L., Bridge, J., Monga, S., \& Baugher, M. (1999). Psychometric properties of the Screen for Child Anxiety Related Emotional Disorders (SCARED): A replication study. Journal of the American Academy of Child and Adolescent Psychiatry, 38, 1230-1236.

Chorpita, B. F., Albano, A. M., \& Barlow, D. H. (1998). The structure of negative emotions in a clinical sample of children and adolescents. Journal of Abnormal Psychology, 107, 74-85.

Chorpita, B. F., Daleiden, E. L., Moffitt, C., Yim, L., \& Umemoto, L. A. (2000). Assessment of tripartite factors of emotion in children and adolescents I: Structural validity and normative data on an affect and arousal scale. Journal of Psychopathology and Behavioral Assessment, 22, 141-160.

Chorpita, B. F., Yim, L., Moffitt, C., Umemoto, L. A., \& Francis, S. E. (2000). Assessment of symptoms of DSM- 
IV anxiety and depression in children: A revised child anxiety and depression scale. Behaviour Research and Therapy, 38, 835-855.

Cole, D. A., Peeke, L. G., Martin, J. M., Truglio, R., \& Seroczynski, A. D. (1998). A longitudinal look at the relation between depression and anxiety in children. Journal of Consulting and Clinical Psychology, 66, 451-460.

Craske, M. G. (1997). Fear and anxiety in children and adolecents. Bulletin of the Menninger Clinic, 61(Suppl. A), A4-A36.

Daleiden, E., Chorpita, B. F., \& Lu, W. (2000). Assessment of tripartite factors of emotion in children and adolescents II: Concurrent validity of the affect and arousal scales for children. Journal of Psychopathology and Behavioral Assessment, 22, 161-182.

Dong, Q., Yang, B., \& Ollendick, T. H. (1994). Fears in Chinese children and adolescents and their relationships to anxiety and depression. Journal of Child Psychology and Psychiatry, 35, 351-363.

Finch, A. J., Lipovsky, J. A., \& Casat, C. D. (1989). Anxiety and depression in children and adolescents: Negative affectivity or separate constructs? In P. C. Kendall, \& D. Watson, Anxiety and depression: Distinctive and overlapping features (pp. 171-202). New York: Academic Press.

Kendall, P. C. (1994). Treating anxiety disorders in children: Results of a randomized clinical trial. Journal of Consulting and Clinical Psychology, 62, 100-110.

King, N. J., Ollendick, T. H., \& Gullone, E. (1991). Negative affectivity in children and adolescents: Relations between anxiety and depression. Clinical Psychology Review, 11, 441-459.

Kovacs, M. (1981). Rating scales to assess depression in school-aged children. Acta Paedopsychiatrica, 46, 305-315.

March, J. S., Conners, C., Arnold, G., Epstein, J., Parker, J. D., Hinshaw, S., Abikoff, H., Molina, B., Wells, K., Newcorn, J., Schuck, S., Pelham, W. E., \& Hoza, B. (1999). The Multidimensional Anxiety Scale for Children (MASC): Confirmatory factor analysis in a pediatric ADHD sample. Journal of Attention Disorders, 3, 85-89.

March, J. S., Parker, J. D., Sullivan, K., Stallings, P., \& Conners, C. (1997). The Multidimensional Anxiety Scale for Children: Factor structure, reliability, and validity. Journal of the American Academy of Child Adolescent Psychiatry, $36,554-565$.

March, J. S., Sullivan, K., \& Parker, J. D. (1999). Test-retest reliability of the Multidimensional Anxiety Scale for Children. Journal of Anxiety Disorders, 13, 349-358.

Meng, X. L., Rosenthal, R., \& Rubin, D. B. (1992). Comparing correlated correlation coefficients. Psychological Bulletin, 111, 172-175.

Muris, P., Gadet, B., Moulaert, V., \& Merckelbach, H. (1998). Correlations between two multidimensional anxiety scales for children. Perceptual and Motor Skills, 87, 269-270.

Muris, P., Merckelbach, H., Gadet, B., Moulaert, V., \& Tierney, S. (1999). Sensitivity for treatment effects of the Screen for Child Anxiety Related Emotional Disorders. Journal of Psychopathology and Behavioral Assessment, 21, 323-335.

Muris, P., Merckelbach, H., Mayer, B., \& Prins, E. (2000). How serious are common childhood fears? Behaviour Research and Therapy, 38, 217-228.

Muris, P., Merckelbach, H., Mayer, B., Van Brakel, A., Thissen, S., Moulaert, V., \& Gadet, B. (1998). The Screen for Child Anxiety Related Emotional Disorders and its relationship to traditional childhood anxiety measures. Journal of Behavior Therapy and Experimental Psychiatry, 29, 327-339.

Muris, P., Merckelbach, H., Schmidt, H., \& Mayer, B. (1999). The revised version of the Screen for Child Anxiety Related Emotional Disorders (SCARED-R): Factor structure in normal children. Personality and Individual Differences, 26, 99-112.

Muris, P., Merckelbach, H., Van Brakel, A., \& Mayer, B. (1999). The Screen for Child Anxiety Related Emotional Disorders (SCARED): Further evidence for its reliability and validity. Anxiety Stress and Coping, 12, 411-425.

Muris, P., Merckelbach, H., Van Brakel, A., Mayer, B., \& Van Dongen, L. (1998). The Screen for Child Anxiety Related Emotional Disorders: Relationship with anxiety and depression in normal children. Personality and Individual Differences, 24, 451-456.

Muris, P., Schmidt, H., \& Merckelbach, H. (2000). Correlations among two self-report questionnaires for measuring DSM-defined anxiety disorder symptoms in children: The Screen for Child Anxiety Related Emotional Disorders and the Spence Children's Anxiety Scale. Personality and Individual Differences, 28, 333-346.

Muris, P., \& Steerneman, P. (2001). The Revised version of the Screen for Child Anxiety Related Emotional Disorders 
(SCARED-R): First evidence for its reliability and validity in a clinical sample. British Journal of Clinical Psychology, 40, 35-44.

Ollendick, T. H. (1983). Reliability and validity of the Revised Fear Survey Schedule for Children (FSSC-R). Behaviour Research and Therapy, 21, 685-692.

Ollendick, T. H., King, N. J., \& Frary, R. B. (1989). Fears in children and adolescents: Reliability and generalizability across gender, age, and nationality. Behaviour Research and Therapy, 27, 19-26.

Ollendick, T. H., Yule, W., \& Ollier, K. (1991). Fears in British children and their relationship to manifest anxiety and depression. Journal of Child Psychology and Psychiatry, 32, 321-331.

Papay, J. P., Costello, R. J., Hedl, J. J., \& Spielberger, C. D. (1975). Effects of trait and state anxiety on the performance of elementary school children in traditional and individualized multiage classrooms. Journal of Educational Psychology, 67, 840-846.

Reynolds, C. R. (1980). Concurrent validity of "What I think and feel": The Revised Children's Manifest Anxiety Scale. Journal of Consulting and Clinical Psychology, 48, 774-775.

Reynolds, C. R. (1982). Convergent and divergent validity of the Revised Children's Manifest Anxiety Scale. Educational and Psychological Measurement, 42, 1205-1212.

Reynolds, C. R., \& Richmond, B. O. (1978). What I think and feel: A revised measure of children's manifest anxiety. Journal of Abnormal Child Psychology, 6, 271-280.

Reynolds, C. R., \& Paget, K. D. (1983). National normative and reliability data for the Revised Children's Manifest Anxiety Scale. School Psychology Review, 12, 324-336.

Spence, S. H. (1997). Structure of anxiety symptoms among children: A confirmatory factor-analytic study. Journal of Abnormal Psychology, 106, 280-297.

Spence, S. H. (1998). A measure of anxiety symptoms among children. Behaviour Research and Therapy, 36, 545-566.

Spielberger, C. D. (1973). Manual for the State-Trait Anxiety Inventory for Children. Palo Alto, CA: Consulting Psychologists Press.

Stallings, P., \& March, J. S. (1995). Assessment. In J. S. March, Anxiety disorders in children and adolescents (pp. 125-147). New York: Guilford Press.

Strauss, C. C. (1993). Anxiety disorders. In T. H. Ollendick, \& M. Hersen, Handbook of child and adolescent assessment (pp. 239-250). Boston: Allyn \& Bacon.

Weems, C. F., Silverman, W. K., Saavedra, L. M., Pina, A. A., \& White Lumpkin, P. (1999). Discrimination of children's phobias using the Revised Fear Survey Schedule for Children. Journal of Child Psychology and Psychiatry, 40, 941-952. 